BMJ Open

Diabetes

Research

\& Care

\section{Cost analysis of the flash monitoring system (FreeStyle Libre 2 ) in adults with type 1 diabetes mellitus}

To cite: Oyagüez I, Merino-Torres JF, Brito M, et al. Cost analysis of the flash monitoring system (FreeStyle Libre 2) in adults with type 1 diabetes mellitus. BMJ Open Diab Res Care 2020;8:e001330. doi:10.1136/ bmjdrc-2020-001330

Presented ay 79th Scientific Sessions. American Diabetes Association (ADA). San Francisco (USA). 2019, 7-11 June

Received 4 March 2020 Revised 21 May 2020 Accepted 26 May 2020
Check for updates

(c) Author(s) (or their employer(s)) 2020. Re-use permitted under CC BY-NC. No commercial re-use. See rights and permissions. Published by BMJ.

For numbered affiliations see end of article.

Correspondence to Itziar Oyagüez;

ioyaguez@porib.com

\section{ABSTRACT}

Introduction Compare cost of the interstitial liquid glucose flash monitoring (FM) system (FreeStyle Libre 2) versus self-monitoring of blood glucose (SMBG) in adults with type 1 diabetes mellitus (T1DM) in Spain.

Research design and methods A model was developed to estimate, with the perspective of the Spanish health system, the annual costs associated with glucose monitoring and hypoglycemic events management in T1DM population, with multiple insulin daily doses (MDI). According to published evidence, rate of severe hypoglycemia (SHE) of 4.90 episodes per patient-year was applied. Reduction of SHE (58.6\%) was modeled associated with FM use. Published rates of hospital care $(20.2 \%)$ and subsequent admission (16\%) were assumed for SHE. The daily consumption of strips and lancets was 9 in patients with SMBG (before and after 4 daily intakes and at bedtime) and 0.5 for FM users (according to IMPACT trial findings). Annual consumption of $26 \mathrm{FM}$ sensors was considered (1 every 14 days). Unit costs (in € of 2019, excluding VAT) were obtained from literature and national databases. Sensitivity analyses $(S A)$ were carried out to evaluate the model robustness.

Results The total annual cost/patient was $€ 4437$ for SMBG and $€ 2526$ for FM. The use of FM would be associated with an annual savings in the costs of monitoring and managing hypoglycemic events of $€ 1911$ per patient-year. In a hypothetical cohort of 1000 patients with T1DM MDI, FM could avoid in 1 year 4900 SHE, 93 hospitalizations for SHE. In addition, the use of FM would generate total savings of up to $€ 1910000$ per year. In the SA with alternative hypoglycemia events rates and use of strips and lancets, and including non-SHE episodes, savings from $€ 370000$ to $€ 1760000$ were observed with FM.

Conclusions The use of the FM system to monitor glucose in adults with T1DM treated with MDI, would reduce hypoglycemic events and would result in cost savings for the health system.

\section{INTRODUCTION}

Diabetes mellitus (DM) is a chronic disease that according to WHO affects $>422$ million people worldwide. ${ }^{1}$ In addition to its great and increasing clinical relevance, DM also has an important economic impact. In Spain,

\section{Significance of this study}

What is already known about this subject?

- Flash monitoring (FM) system for glucose monitoring in patients with diabetes mellitus has demonstrated to be effective and cost-savings in some healthcare settings.

What are the new findings?

- This analysis showed that due to the avoided hypoglycemic episodes, and cost neutrality in the monitoring consumables, the use of FM system in adult population with diabetes could be associated with annual savings for the Spanish National System.

How might these results change the focus of research or clinical practice?

- These results could be useful in the decissionmaking process related to the public reimbursement and the resource allocation in the diabetes mellitus field.

- Using FM system in T1DM population could avoid severe hypoglycemic episodes (up to 4900 in a 1000 patients cohort annually).

- In Spain, FM system could be associated with annual savings up to $€ 1900$ per patient for the National Health System.

it has been estimated that the direct costs associated with the disease may reach $€ 5100$ million, representing $8 \%$ of global public health expenditure. ${ }^{2}$

The clinical management of type $1 \mathrm{DM}$ (T1DM) is oriented toward the individualization of therapy, including the promotion of an adequate lifestyle together with the use of insulin-based treatments ${ }^{3}$ adapted to the patient characteristics and preferences.

Health outcomes may be improved through interventions targeted to a triad of therapeutic goals: the reduction of glycated hemoglobin (HbA1c) levels, the limitation of glycemic variability and the reduction of hypoglycemic episodes. 
The development of hypoglycemia is associated with increased complications and morbidity-mortality in patients with $\mathrm{DM},{ }^{4}$ and moreover has an impact on patient productivity and increases the overall associated costs. $^{5}$

However, despite the pharmacotherapeutic advances of recent years, a proportion of patients are still unable to maintain their blood glucose levels within the recommended limits. ${ }^{67}$

Blood glucose monitoring has been shown to be useful for controlling the HbAlc levels, and there is evidence that an increase in monitoring frequency contributes to achieve the aforementioned therapeutic objectives. ${ }^{8}$ However, current monitoring based on the self-monitoring of blood glucose (SMBG) has significant limitations, ${ }^{9}$ especially low patient adherence to the monitoring recommendations established by the national ${ }^{10}$ and international scientific societies. ${ }^{11}$

The barriers complicating patient adherence to the SMBG recommendations include physical (related to pain and discomfort), psychological (fear, frustration), social (interference with lifestyle) and economic factors. ${ }^{12} 13$

FreeStyle Libre 2 is an interstitial fluid glucose flash monitoring (FM) system with optional alarms, marketed and available in Spain, being fully reimbursed under the Basic Services Portfolio of the Spanish National Health System (Sistema Nacional de Salud) for T1DM population. ${ }^{14}$ FreeStyle Libre is fully or partially reimbursed in 36 markets. The FM system is accompanied by a digital ecosystem with free mobile applications (FreeStyle Libre Link and FreeStyle LibreLinkUp) and virtual software (LibreView) that simplify glucose monitoring, allowing better management of the disease and facilitating connection between professionals and patients.

The clinical evidence of the FM system has been evaluated in randomized clinical trials in both the T1DM population of the IMPACT study ${ }^{15} 16$ and in patients with type $2 \mathrm{DM}$ (T2DM) in the REPLACE trial. ${ }^{17}$

In the IMPACT study, the patients in the FM arm experienced a statistically significant decrease in the number and mean duration of hypoglycemic episodes compared with the patients in the SMBG arm. ${ }^{15}$ In addition, the users of the FM system reduced their need for fingerprick glycemia measurements by up to $91 \%$ vs SMBG. These results were also seen for the subgroup of patients with T1DM with multiple dose insulin (MDI) therapy.

The lesser consumption of healthcare resources associated with the FM system, resulting from fewer hypoglycemic episodes and a lesser consumption of SMBG supplies, could lower the overall cost of management in patients with T1DM subjected to intensive insulin therapy. ${ }^{17}$

The present study conducted a cost analysis of the FM system versus SMBG in adults with T1DM and MDI therapy in Spain.

\section{RESEARCH DESIGN AND METHODS}

A cost analysis model was developed to estimate the economic impact associated with glucose monitoring and the management of hypoglycemic events in patients using the FM system as compared with standard practice based on SMBG only. FreeStyle Libre 2 has been considered in the analysis, as this version of the FM system will be available in Spain since the beginning of 2020 .

The analysis comprised a hypothetical cohort of 1000 adult patients ( $>18$ years) with T1DM and treated with MDI.

Considering the perspective of the Spanish National Health System, an estimate was made of the annual costs derived from the consumption of resources associated with glucose monitoring (strips, lancets and FM sensors) and the management of severe hypoglycemia .

The values of the parameters, obtained from the published literature, were validated by a panel of six endocrinologists with expertise in the management of patients with diabetes.

A review of the scientific literature was made to identify the available evidence on hypoglycemia rates in the population with T1DM.

In line with the widely accepted definition, severe hypoglycemic episodes were regarded as those requiring help from another person. ${ }^{18} 19$

A wide variation of severe hypoglycemia rates per patient-year were found during the literature review. For the base case, the Hypoglycaemia Assessment Tool (HAT) study, an observational study conducted in 24 countries, was chosen in view of its robustness (sample size, multicentric nature and representativeness of the Spanish population). ${ }^{20}$ The mentioned study estimated an annual incidence of 4.90 severe hypoglycemic episodes per patient. ${ }^{20}$

The efficacy of the FM system in T1DM was evaluated by the IMPACT study, a phase III, randomized, multicenter clinical trial that included 328 patients from 23 diabetes centers in 5 European countries (Austria, Germany, Spain, the Netherlands and Sweden). ${ }^{15} 16$ The results of the trial evidenced reductions in hypoglycemia associated with the use of the FM system $(-58.6 \%$ for episodes with glucose level $<2.2 \mathrm{mmol} / \mathrm{L}$ (40 mg/ dL) ). ${ }^{16}$ Despite that the International Hypoglycemia Study Group published a proposal for reporting hypoglycemia in clinical trials, ${ }^{21}$ based on three levels; in the IMPACT trial, ${ }^{16}$ severe hypoglycemic episodes (requiring third-party assistance) were not specifically reported. For the purposes of the present analysis, we analyzed level 1, according the American Diabetes Association (ADA) proposed classification equating severe hypoglycemia to episodes with glucose level $<2.2 \mathrm{mmol} / \mathrm{L}(40 \mathrm{mg} / \mathrm{dL})$ (table 1).

For the management of hypoglycemic events, hospital care was considered necessary in $20.2 \%$ of the cases of severe hypoglycemia, with subsequent hospital admission in $16 \%$ of the cases. ${ }^{22}$ 
Table 1 Baseline characteristics of the patients and main results of the IMPACT study ${ }^{16}$

\begin{tabular}{lll}
\hline Parameter & SMBG $(\mathbf{n = 8 0})$ & FM system $(\mathbf{n = 8 1})$ \\
\hline Age, years: mean (range) & $44(34-53)$ & $42(32-53)$ \\
Duration of diabetes, years: mean (range) & $19(11-31)$ & $19(14-25)$ \\
Baseline HbA1c, \%: mean \pm SD & $6.7 \pm 0.6$ & $6.7 \pm 0.5$ \\
Baseline daily frequency of SMBG: mean \pm SD & $5.6 \pm 1.9$ & $5.5 \pm 2.0$ \\
Final daily frequency of SMBG: mean \pm SD & $5.5 \pm 2.6$ & $0.5 \pm 1.0$ \\
Number of episodes with glucose $<2.2 \mathrm{mmol} / \mathrm{L}(40 \mathrm{mg} / \mathrm{dL}):$ & Baseline: $0.49 \pm 0.52$ & Baseline: $0.44 \pm 0.48$ \\
mean \pm SD & Final: $0.52 \pm 0.63$ & Final: $0.20 \pm 0.32$ \\
& Difference FM vs SMBG: $-58.6 \%$ \\
Number of episodes with glucose $<3.9 \mathrm{mmol} / \mathrm{L}(70 \mathrm{mg} / \mathrm{dL}):$ & Baseline: $1.72 \pm 0.75$ & Baseline: $1.80 \pm 0.80$ \\
mean \pm SD & Final: $1.78 \pm 0.78$ & Final: $1.23 \pm 0.69$ \\
& Difference FM vs SMBG: $-32.8 \%$
\end{tabular}

FM, flash monitoring; HbA1c, glycated hemoglobin; SMBG, self-monitoring of capillary blood glucose.

In line with the current recommendations for patients with T1DM referred to glucose monitoring before and after food intake and at bedtime, ${ }^{10}$ an optimum consumption of nine strips a day was considered in patients with SMBG (assuming four daily meals). The use of a lancet was assumed in each SMBG measurement, thereby representing nine lancets a day.

Based on the IMPACT study, ${ }^{16}$ at the end of the trial the users of the FM system performed only $0.5 \pm 1.0 \mathrm{SMBG}$ test a day.

In the cohort of patients with T1DM with MDI that used the FM system, 26 FM system sensors were estimated to be used annually, considering the recommendations of the manufacturer to replace the sensor every 14 days.

The unit costs (in $€$ of 2019 and excluding VAT) were obtained from the reviewed literature and national databases (€0.28/strip, €0.09/lancet, €43.27/FM sensor, $€ 3773.98$ /severe hypoglycemic episode with hospital admission, ${ }^{23} € 1779.50 /$ severe hypoglycemic episode with hospital care but no admission, ${ }^{24} € 293.23$ /severe hypoglycemic episode without hospital care. ${ }^{25}$

\section{Sensitivity analysis}

Sensitivity analyses (SAs) were performed to evaluate the robustness of the model by modifying the parameters with the greatest uncertainty, with observation of the influence of these modifications on the results.

Given the uncertainty around the severe hypoglycemia rate per-patient-year, SA with alternatives values found in the literature were carried out: 3.4 severe hypoglycemic episodes referred to the population of northern Europe and Canada in the HAT study ${ }^{26}$ (SA1); 3.2 severe hypoglycemic episodes according to a study of the UK Hypoglycaemia Group ${ }^{27}$ (SA2); 1.05 severe hypoglycemic episodes according to available meta-analysis data ${ }^{28}$ (SA3) and 0.9 severe hypoglycemic episodes recorded in a Spanish national study ${ }^{29}$ (SA4).

An additional scenario was also tested, considering non-severe hypoglycemic events, equated to those episodes with glucose level $\geq 2.2 \mathrm{mmol} / \mathrm{L}(40 \mathrm{mg} / \mathrm{dL})$ and $<3.9 \mathrm{mmol} / \mathrm{L}(70 \mathrm{mg} / \mathrm{dL})$ (SA5). A rate of 68.62 non-severe hypoglycemic episodes per patient-year reported on the HAT study ${ }^{20}$ was considered. Reduction of $32.8 \%$ for episodes with glucose level $<3.9 \mathrm{mmol} / \mathrm{L}$ (70 $\mathrm{mg} / \mathrm{dL}$ ) reported in the IMPACT trial, ${ }^{16}$ for FM users was applied to non-severe hypoglycemic events. Unitary cost of $€ 7.25 /$ non-severe hypoglycemic episode ${ }^{30}$ was used for the computations.

Different SAs were also performed regarding the daily consumption of strips and lancets in patients with SMBG only, with consideration of the following: six strips and lancets a day (coinciding with the criterion used to assess reimbursement of the FM system in Spain (children or adults with T1DM, MDI including patients with continuous subcutaneous insulin infusion and at least six glycemia controls a day)) (SA6); nine strips a day with half the lancets (4.5/day) (SA7) and six strips a day with half the lancets (3/day) (SA8). Lastly, an analysis was made without considering the unit costs associated with the use of strips $(€ 0)$ and lancets $(€ 0)$ (SA9).

\section{RESULTS}

The estimated total annual cost was $€ 4437$ per patient with SMBG and €2526 per patient with FM.

The costs per patient-year associated with glucose monitoring were $€ 1216$ with SMBG and $€ 1193$ with the FM system-this representing a decrease of $€ 24(-1.9 \%)$ per patient using the FM system. The saving from the reduction of strip and lancet consumption was $€ 1149$ (94.4\% reduction), which compensated the FM system sensor acquisition cost, estimated to be $€ 1125$ per patient-year.

The management of severe hypoglycemic episodes represented an annual cost of $€ 3220$ per patient with SMBG. In patients with FM, the annual cost was $€ 1333$ per patient. The hypoglycemic episodes prevented with the FM system would result in a cost saving of $€ 1887$ $(-58.6 \%)$. 


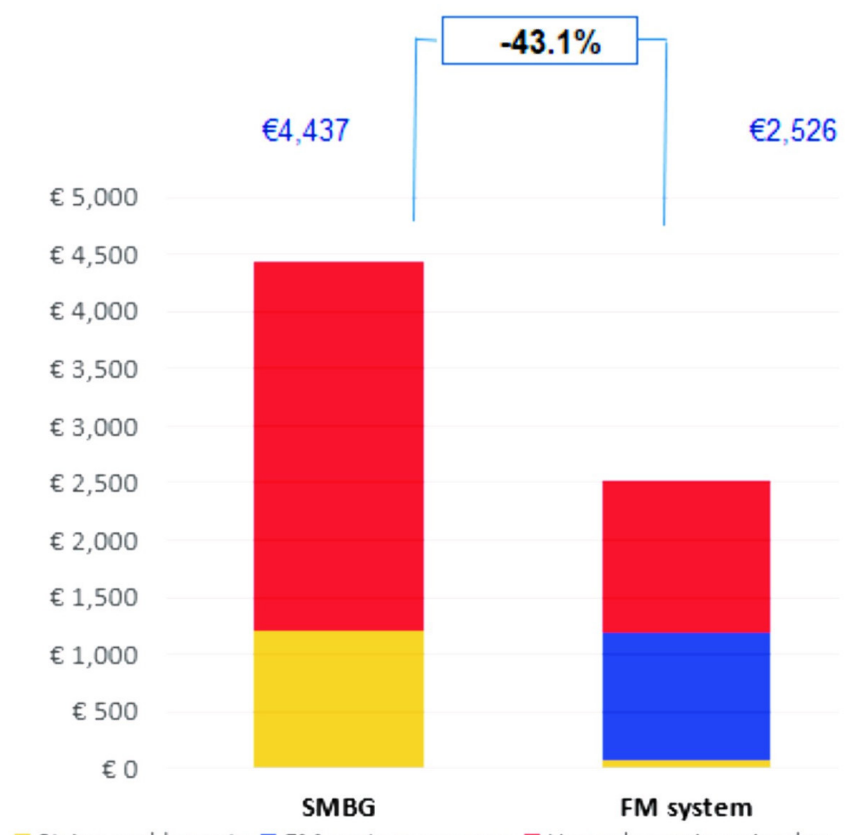

Intrips and lancets FM system sensors Hypoglycemia episodes

Figure 1 Detailed annual costs per patient. FM, flash monitoring; SMBG, self-monitoring of blood glucose.

Use of the FM system would be associated with an annual total cost saving of $€ 1911(-43.1 \%)$ as compared with SMBG (figure 1 and table 2).

In a cohort of 1000 patients with T1DM treated with MDI, a total of 4900 severe hypoglycemic episodes would occur using SMBG vs 2029 with the FM system. Thus, the FM system would avoid 2871 severe hypoglycemic episodes a year (58.6\% reduction), among them 93 cases of hospitalizations by SHE (table 3 ).

The use of the FM system would generate total annual savings per 1000 patients of up to $€ 1910764$ compared with SMBG (table 3 ) - this representing a $43.1 \%$ reduction in overall costs.

For every 1000 patients with T1DM treated with MDI, the results of the SAs revealed annual savings associated with the FM system of $€ 1333089(-38.6 \%)$ on using the alternative severe hypoglycemia rate (3.4 episodes per patient-year), ${ }^{26}$ derived from the reduction of 1992 severe hypoglycemic episodes. With the hypoglycemia rate per patient-year in the study of the UK Hypoglycaemia Group ${ }^{27}$ (3.2 severe hypoglycemic episodes), the
FM system would allow savings of $€ 1256065$ in 1000 patients, that is, a decrease in overall cost of $-37.8 \%$ as compared with the use of SMBG. The use of episode rates per patient-year of the meta-analysis ${ }^{28}$ (1.05 severe hypoglycemic episodes) or the Spanish national study $(0.9$ severe episodes ${ }^{29}$ would continue to reveal savings with the FM system of $€ 428064$ and $€ 370296$, respectively, compared with use of SMBG alone, in a cohort of 1000 patients with T1DM and receiving MDI.

In the additional scenario considering also non-severe hypoglycemic episodes, total annual cost resulted $€ 4$ 934038 and $€ 2869261$ for the 1000 patient-cohort with SMBG and FM system, respectively. The use of FM system would avoid 24115 hypoglycemic episodes a year. Of these avoided hypoglycemic episodes, 2871 would correspond to severe episodes (58.6\% reduction), and 21243 to non-severe episodes (31.0\% reduction). Cost savings would be up to $€ 2064777$ per year with the use of FM systems in 1000 patients with T1DM treated with MDI, as compared with SMBG strategy.

The modifications in daily use of strips and lancets also produced a saving associated with the use of the FM system versus SMBG of $€ 1505336$ a year (37.3\% reduction), considering six strips and six lancets a day. The analyses with 9 strips and 4.5 lancets a day and 6 strips and 3 lancets a day revealed savings of $€ 1761358$ and $€ 1405733$, respectively. In the last SA, considering that the strips and lancets would have no cost for the Spanish National Health System, the saving associated with the FM system versus SMBG was estimated to be $€ 762053$ a year $(23.7 \%$ reduction) (table 4$)$.

\section{CONCLUSIONS}

The present analysis shows the FM system with optional alarms to be a strategy resulting in savings in terms of the consumption of glucose monitoring resources. The cost findings suggest that utilization of the FM system would lead to an overall reduction in associated costs in patients with T1DM treated with MDI. Based on the assumptions of this model, the use of the FM system would cut the total annual cost per patient by $€ 1911$ $(43.1 \%)$, which could generate annual savings for the Spanish National Health System of more than $€ 2$ million per cohort of 1000 treated patients.

Table 2 Annual costs for patient with T1DM

\begin{tabular}{|c|c|c|c|c|}
\hline \multirow[b]{2}{*}{ Costs } & \multirow[b]{2}{*}{ SMBG } & \multirow[b]{2}{*}{ FM system } & \multicolumn{2}{|c|}{ Difference FM system vs SMBG } \\
\hline & & & Absolute & $\%$ \\
\hline Cost of blood glucose monitoring & $€ 1216$ & $€ 1193$ & $€-23.7$ & -1.9 \\
\hline Cost of strips and lancets & $€ 1216$ & $€ 68$ & $€-1149$ & -94.4 \\
\hline Cost of FM system sensors & $€ 0$ & $€ 1125$ & $€ 1125$ & \\
\hline Cost of management of severe hypoglycemia episodes & $€ 3220$ & $€ 1333$ & $€-1887$ & -55.1 \\
\hline Total cost & $€ 4437$ & $€ 2526$ & $€-1911$ & -43.1 \\
\hline
\end{tabular}

FM, flash monitoring; SMBG, self-monitoring of blood glucose; T1DM, type 1 diabetes mellitus. 
Table 3 Hypoglycemia episodes and annual costs for a cohort of 1000 patients with T1DM with MDI

\begin{tabular}{llll}
\hline Parameter & SMBG & FM system & $\begin{array}{l}\text { Absolute difference FM system } \\
\text { vs SMBG (percentage variation) }\end{array}$ \\
\hline Severe hypoglycemia episodes & 4900 & 2029 & $-2871(-58.6 \%)$ \\
\hline SH with hospital admission & 158 & 65 & $-93(-58.6 \%)$ \\
\hline SH with hospital care, no admission & 830 & 344 & $-486(-58.6 \%)$ \\
\hline SH without hospital care & 3912 & 1620 & $-2293(-58.6 \%)$ \\
\hline Cost of glucose monitoring & $€ 1216283$ & $€ 1192591$ & $€-23691(-1.9 \%)$ \\
\hline Cost of strips and lancets & $€ 1216283$ & $€ 65571$ & $€-1148711(-94.4 \%)$ \\
\hline Cost of FM system sensors & $€ 0$ & $€ 1125020$ & $€ 1125020(100.0 \%)$ \\
\hline Cost of management of severe hypoglycemic episodes & $€ 3220260$ & $€ 1333188$ & $€-1887073(-58.6 \%)$ \\
\hline Total cost & $€ 4436543$ & $€ 2525779$ & $€-1910764(-43.1 \%)$ \\
\hline
\end{tabular}

FM, flash monitoring; MDI, multiple dose insulin; SH, severe hypoglycemia; SMBG, self-monitoring of capillary glucose; T1DM, type 1 diabetes mellitus.

The cost savings associated with the FM system have also been observed in other settings such as the UK in patients with $\mathrm{T} 1 \mathrm{DM},{ }^{31}$ and also in patients with T2DM. ${ }^{32}$ Utilization of the FM system in the population with T1DM was associated with annual savings of $£ 234.28 /$ patient $^{31}$ in a scenario with 10 daily SMBG measurements as a reflection of the National Institute for Health and Care Excellence recommendations regarding patients with T1DM. ${ }^{11}$

The reduction of hypoglycemic episodes is the parameter that contributes most to the estimated cost savings.

There are some limitations around this parameter. The first one is related to the uncertainty about the incidence of hypoglycemia. The broad range of values found in the literature is very likely due to the existence of differences in the methodology and criteria used in the different studies. In the present analysis, the expert panel selected a multicenter (2004 healthcare centers), multinational (24 countries) and large study (27 585 patients with diabetes; 8022 patients with T1DM) ${ }^{20} 26$ as the most robust data source. However, in all the SAs performed with alternative hypoglycemia rates, utilization of the FM system was always associated with savings in these patients ranging from $€ 370000$ to $€ 1333000$ for a cohort of 1000 subjects. Even in the scenario characterized by no cost associated with blood glucose monitoring strips and lancets, the hypoglycemic events avoided would generate savings for the healthcare system up to $€ 762000$ in 1000 patients.

The IMPACT trial ${ }^{16}$ reported reductions of biochemical hypoglycemia in association with FM system use that in the present analysis were applied to the incidence of clinical hypoglycemias. This is a controversial issue, because evidence about relationship between low glucose level and symptomatic hypoglycemic episodes is limited, although a recent publication has concluded that the occurrence of biochemical hypoglycemia $(<3.9$

Table 4 Results of the sensitivity analyses

\begin{tabular}{|c|c|c|c|}
\hline & \multicolumn{3}{|c|}{ Total annual cost for 1000 patients with T1DM with MDI } \\
\hline & SMBG & FM system & $\begin{array}{l}\text { Absolute difference } \\
\text { FM system vs SMBG } \\
\text { (percentage variation) }\end{array}$ \\
\hline Base case & $€ 4436543$ & $€ 2525779$ & $€-1910764(-43.1 \%)$ \\
\hline SA1 (3.4 severe hypoglycemic episodes/patient-year) & $€ 3450749$ & $€ 2117660$ & $€-1333089(-38.6 \%)$ \\
\hline SA2 (3.2 severe hypoglycemic episodes/patient-year) & $€ 3319310$ & $€ 2063244$ & $€-1256065(-37.8 \%)$ \\
\hline SA3 (1.05 severe hypoglycemia episodes/patient-year) & $€ 1906338$ & $€ 1478274$ & $€-428064(-22.5 \%)$ \\
\hline SA4 (0.9 severe hypoglycemia episodes/patient-year) & $€ 1807759$ & $€ 1437462$ & $€-370296(-20.5 \%)$ \\
\hline SA5 (including severe and non-severe hypoglycemia) & $€ 4934038$ & $€ 2869261$ & $€-2064777(-41.85 \%)$ \\
\hline SA6 (6 strips and lancets a day for SMBG) & $€ 4031115$ & $€ 2525779$ & $€-1505336(-37.3 \%)$ \\
\hline SA7 (9 strips and 4.5 lancets a day for SMBG) & $€ 4287137$ & $€ 2525779$ & $€-1761358(-41.1 \%)$ \\
\hline SA8 (6 strips and 3 lancets a day for SMBG) & $€ 3931512$ & $€ 2525779$ & $€-1405733(-35.8 \%)$ \\
\hline SA9 (no cost associated with strips and lancets) & $€ 3220260$ & $€ 2458208$ & $€-762053(-23.7 \%)$ \\
\hline
\end{tabular}

FM, flash monitoring; MDI, multiple dose insulin; SA, sensitivity analysis; SMBG, self-monitoring of capillary glucose; T1DM, type 1 diabetes mellitus. 
or $3 \mathrm{mmol} / \mathrm{L}$ ) is associated with an increased risk of severe hypoglycemic events. ${ }^{33}$

For the better addressing of the issue of hypoglycemic risk, the International Hypoglycemia Study Group recommended to the diabetes community the adoption of common glucose levels when reporting outcomes about hypoglycemia in studies. ${ }^{21}$ However, since in the trial used in this analysis as efficacy source, hypoglycemic events were not specifically reported, an assumption was needed equating those episodes with glucose levels $<2.0 \mathrm{mmol} / \mathrm{L}(40 \mathrm{mg} / \mathrm{dL})$ to hypoglycemic episodes requiring external assistance. Given the results of the IMPACT trial, this assumption represents a conservative scenario, because the proposed definition for severe hypoglycemic episodes could also be applied to events with glucose levels $\geq 2.0$ $\mathrm{mmol} / \mathrm{L}(40 \mathrm{mg} / \mathrm{dL})$. Given the lack of additional evidence, the present analysis assumes that findings of the IMPACT trial ${ }^{16}$ are generalizable to the population of patients with T1DM with MDI, although the eligible population of the IMPACT ${ }^{16}$ was restricted to patients with HbAlc level of $7.5 \%$ or lower. Further development of randomized controlled studies including patients with $\mathrm{HbA1c}$ level $>7.5 \%$ would be required to confirm that and being the source for updating the analysis. We have also assumed that the IMPACT results are fully transferable to FreeStyle Libre 2, but with FreeStyle Libre 2 optional alarms and the improved accuracy performance, the use of FreeStyle Libre 2 could result in a higher reduction of severe hypoglycemia.

Regardless of the avoided hypoglycemic episodes, use of the FM system was associated with a decrease in the number of SMBG measurements required by the patients, and this alone generated cost reductions of $-1.9 \%$ as compared with the use of SMBG alone. This resulted in direct cost savings for the Spanish National Health System of $€ 24000$ per 1000 patient-year.

There is not discussion about the value of the glucose monitoring on the diabetes control, and the strong association between higher SMBG frequency and lower HbAlc levels, ${ }^{34}$ however several scientific publications ${ }^{12} 35$ revealed a poor follow-up of the recommendations stated in the current clinical guidelines. ${ }^{10} 11$ Considering possible low adherence to these monitoring recommendations, SAs with variations in optimum consumption were performed. Although the daily number of SMBG measurements in patients with T1DM with MDI was lower than the nine recommended daily measurements, the savings derived from the avoided hypoglycemic episodes would compensate for the costs of acquiring the sensors of the FM system.

The low adherence of patients to the monitoring recommendations is justified by a wide variety of reasons among which lack of time, invasiveness and needle phobia are included. ${ }^{35} 36$ The features of FM system could overcome some of these barriers, ${ }^{37}$ contributing to increase the daily number of glucose determinations.
The FM system has been positively evaluated in application to patients with T1DM and T2DM by health assessment agencies in a number of countries and regions (France, Norway, Scotland, Sweden, UK, Wales, etc), and published cost-effectiveness analysis have shown the efficiency of the FM system in several settings. ${ }^{38-43}$

The use of the FM system as a substitute for test strips in SMBG may result in savings for the National Health system, while also improving disease control and patient quality of life. It would be particularly interesting to conduct future studies and/or registries on the use of this technology in real life, with a view to obtaining information on the clinical, economic and quality of life repercussions for patients in our setting, particularly considering that the digital ecosystem accompanying the FreeStyle Libre 2 system (LibreView, FreeStyle Libre Link, FreeStyle Libre LinkUp) can also have an impact on the patients, their relatives and the healthcare professionals.

In conclusion, the use of the glucose FM system (FreeStyle Libre 2) represents an efficient strategy for the Spanish National Health System, thanks to the savings it can generate, linked to both the decrease in hypoglycemic episodes and to the direct cost savings in blood glucose monitoring.

Considering the assumptions and costs described, in comparison with SMBG, the FM system would potentially allow cost savings of up to $€ 1910000$ per year in a cohort of 1000 patients with T1DM treated with MDI in Spain.

\section{Author affiliations}

${ }^{1}$ Pharmacoeconomics \& Outcomes Research Iberia, Pozuelo de Alarcon, Madrid, Spain

${ }^{2}$ Department of Medicine, Universitat de València Facultat de Medicina i

Odontologia, Valencia, Comunitat Valenciana, Spain

${ }^{3}$ Endocrinology and Nutrition, La Fe University and Polytechnic Hospital, Valencia, Spain

${ }^{4}$ Endocrinology and Nutrition, Puerta de Hierro University Hospital of Majadahonda, Majadahonda, Madrid, Spain

${ }^{5}$ Endocrinology and Nutrition, Cruces University Hospital, Barakaldo, País Vasco Spain

${ }^{6}$ Division of Pediatric Endocrinology, Hospital Sant Joan de Deu, Barcelona, Catalunya, Spain

${ }^{7}$ Endocrinology and Nutrition Unit, Segovia General Hospital, Segovia, Spain ${ }^{8}$ Department of Endocrinology and Nutrition, University Hospital Complex Badajoz, Badajoz, Extremadura, Spain

Contributors 10 developed the model, reviewed the scientific literature, performed the analysis and drafted the manuscript. FG-P, JFM-T, MB, FM-P, VB and RC-H validated the model structure and the inputs and provided information about clinical management of patients with diabetes mellitus in Spain. All the authors contributed to interpretation of the results and reviewed and approved the final version of the manuscript.

Funding Abbott Diabetes Care provided unconditioned financial support for performing the analysis.

Disclaimer The shape of the circle sensor unit, FreeStyle, Libre, and related brand marks are owned by Abbott.

Competing interests Abbott Diabetes Care provided unconditioned financial support for performing the analysis. IO is an employee of PORIB, a consultant specialized in the economic evaluation of healthcare interventions, who provided 
technical and editorial support for conducting the study. FG-P, JFM-T, MB, FM-P, VB and RC-H received payment from Abbott Diabetes Care for consultant activities related to validation of the parameters and results. None of them received financial compensation for review and co-authorship of this manuscript. All the authors contributed to interpretation of the results and reviewed and approved the final version of the manuscript.

Patient consent for publication Not required.

Provenance and peer review Not commissioned; externally peer reviewed.

Data availability statement There are no data in this work.

Open access This is an open access article distributed in accordance with the Creative Commons Attribution Non Commercial (CC BY-NC 4.0) license, which permits others to distribute, remix, adapt, build upon this work non-commercially, and license their derivative works on different terms, provided the original work is properly cited, appropriate credit is given, any changes made indicated, and the use is non-commercial. See: http://creativecommons.org/licenses/by-nc/4.0/.

ORCID iDs

Itziar Oyagüez http://orcid.org/0000-0002-3047-6152

Juan Francisco Merino-Torres http://orcid.org/0000-0002-0191-4504

\section{REFERENCES}

1 Lovic D, Piperidou A, Zografou I, et al. The growing epidemic of diabetes mellitus. Curr Vasc Pharmacol 2019.

2 Lopez-Bastida J, Boronat M, Moreno JO, et al. Costs, outcomes and challenges for diabetes care in Spain. Global Health 2013;9:17.

3 Escobar-Jiménez F. Guías clínicas en diabetes mellitus tipo 1. Endocrinología y Nutrición 2009;56:15-17.

4 Zoungas S, Patel A, Chalmers J, et al. Advance Collaborative Group. severe hypoglycemia and risks of vascular events and death. $N$ Engl J Med 2010;363:1410-8.

5 Brod M, Christensen T, Thomsen TL, et al. The impact of nonsevere hypoglycemic events on work productivity and diabetes management. Value Health 2011;14:665-71.

6 Baena G, Carral F, del Mar Roca M, et al. ¿Es posible alcanzar en La práctica clínica Los objetivos de control metabólico establecidos para pacientes Con diabetes mellitus tipo 1. Endocrinología y Nutrición 2008:55:442-7.

7 Idris I, Peng X, He X, et al. The trend of high-dose insulin usage among patients with diabetes in the UK: a retrospective study. Diabetes Ther 2018;9:2245-57.

8 Hansen MV, Pedersen-Bjergaard U, Heller SR, et al. Frequency and motives of blood glucose self-monitoring in type 1 diabetes. Diabetes Res Clin Pract 2009;85:183-8.

9 Karter AJ, Parker MM, Moffet $\mathrm{HH}$, et al. Longitudinal study of new and prevalent use of self-monitoring of blood glucose. Diabetes Care 2006;29:1757-63.

10 Menéndez Torre E, Tartón García T, Ortega Millán C, et al. Recomendaciones 2012 de la Sociedad Española de diabetes sobre La utilización de tiras reactivas para La medición de la glucemia capilar en personas Con diabetes. Avances en Diabetología 2012;28:3-9

11 National Institute for Health and Care Excellence. Type 1 diabetes in adults: diagnosis and management Disponible en:acceso agosto 2019. Available: https://www.nice.org.uk/guidance/ng17 [Accessed Jun 2017].

12 Vincze G, Barner JC, Lopez D. Factors associated with adherence to self-monitoring of blood glucose among persons with diabetes. Diabetes Educ 2004;30:112-25.

13 Vidal Flor M, Jansà Morató M, Galindo Rubio M, et al. Factors associated to adherence to blood glucose self-monitoring in patients with diabetes treated with insulin. The dapa study. Endocrinol Diabetes Nutr 2018;65:99-106.

14 Ministerio de Sanidad, Consumo Y Bienestar social. Nota de prensa. Ministerio Y CC.AA. Han aprobado El plan de Abordaje de Terapias Avanzadas Y La priorización de cinco colectivos para La inclusión del sistema flash de monitorización de glucosa para adultos Con diabetes tipo1. Disponible en, 2019. Available: https://www.mscbs. gob.es/gabinete/notasPrensa.do?id $=4430$

15 Bolinder J, Antuna R, Geelhoed-Duijvestijn P, et al. Novel glucosesensing technology and hypoglycaemia in type 1 diabetes: a multicentre, non-masked, randomised controlled trial. Lancet 2016;388:2254-63.

16 Oskarsson P, Antuna R, Geelhoed-Duijvestijn P, et al. Impact of flash glucose monitoring on hypoglycaemia in adults with type 1 diabetes managed with multiple daily injection therapy: a pre-specified subgroup analysis of the impact randomised controlled trial. Diabetologia 2018;61:539-50.

17 Haak T, Hanaire H, Ajjan R, et al. Flash glucose-sensing technology as a replacement for blood glucose monitoring for the management of insulin-treated type 2 diabetes: a multicenter, open-label randomized controlled trial. Diabetes Ther 2017;8:55-73.

18 Seaquist ER, Anderson J, Childs B, et al. Hypoglycemia and diabetes: a report of a Workgroup of the American diabetes association and the endocrine Society. Diabetes Care 2013;36:1384-95.

19 Mezquita-Raya P, Reyes-García R, Moreno-Pérez O, et al. Grupo de trabajo de diabetes mellitus de la Sociedad Española de Endocrinología Y Nutrición (seen). Documento de posicionamiento: evaluación Y manejo de la hipoglucemia en El paciente Con diabetes mellitus. Grupo de Trabajo de diabetes mellitus de la Sociedad Española de Endocrinología Y Nutrición. Endocrinol Nutr 2013;60:517.e1-517.e18.

20 Khunti K, Alsifri S, Aronson R, et al. Rates and predictors of hypoglycaemia in 27585 people from 24 countries with insulintreated type 1 and type 2 diabetes: the global HAT study. Diabetes Obes Metab 2016;18:907-15

21 International Hypoglycaemia Study Group. Glucose concentrations of less than $3.0 \mathrm{mmol} / \mathrm{l}(54 \mathrm{mg} / \mathrm{dl})$ should be reported in clinical trials: a joint position statement of the American Diabetes Association and the European Association for the Study of Diabetes. Diabetologia 2017;60:3-6.

22 Lammert M, Hammer M, Frier BM. Management of severe hypoglycaemia: cultural similarities, differences and resource consumption in three European countries. J Med Econ 2009;12:269-80.

23 Crespo C, Brosa M, Soria-Juan A, et al. Costes directos de la diabetes mellitus $Y$ de Sus complicaciones en España (estudio SECCAID: Spain estimated cost Ciberdem-Cabimer in diabetes). Avances en Diabetología 2013;29:182-9.

24 Barranco RJ, Gomez-Peralta F, Abreu C, et al. Incidence and care-related costs of severe hypoglycaemia requiring emergency treatment in Andalusia (Spain): the PAUEPAD project. Diabet Med 2015;32:1520-6.

25 Hammer M, Lammert M, Mejías SM, et al. Costs of managing severe hypoglycaemia in three European countries. J Med Econ 2009;12:281-90.

26 Khunti K, Cigrovski Berković M, Ludvik B, et al. Regional variations in definitions and rates of hypoglycaemia: findings from the global HAT observational study of 27585 people with type 1 and insulin-treated type 2 diabetes mellitus. Diabet Med 2018. doi:10.1111/dme.13662. [Epub ahead of print: 05 May 2018]

27 UK Hypoglycaemia Study Group. Risk of hypoglycaemia in types 1 and 2 diabetes: effects of treatment modalities and their duration. Diabetologia 2007:50:1140-7.

28 Edridge CL, Dunkley AJ, Bodicoat DH, et al. Prevalence and incidence of hypoglycaemia in 532,542 people with type 2 diabetes on oral therapies and insulin: a systematic review and meta-analysis of population based studies. PLOS One 2015;10:e0126427.

29 Orozco-Beltrán D, Mezquita-Raya P, Ramírez de Arellano A, et al. Self-Reported frequency and impact of hypoglycemic events in Spain. Diabetes Ther 2014;5:155-68.

30 Parekh W, Hoskins N, Baker-Knight J, et al. The economic burden of insulin-related hypoglycemia in Spain. Diabetes Ther 2017:8:899-913.

31 Hellmund R, Weitgasser R, Blissett D. Cost calculation for a flash glucose monitoring system for UK adults with type 1 diabetes mellitus receiving intensive insulin treatment. Diabetes Res Clin Pract 2018;138:193-200.

32 Hellmund R, Weitgasser R, Blissett D. Cost Calculation for a Flash Glucose Monitoring System for Adults with Type 2 Diabetes Mellitus Using Intensive Insulin - a UK Perspective. Eur Endocrinol 2018;14:86-92.

33 Beck RW, Bergenstal RM, Riddlesworth TD, et al. The association of biochemical hypoglycemia with the subsequent risk of a severe hypoglycemic event: analysis of the DCCT data set. Diabetes Technol Ther 2019;21:1-5.

34 Miller KM, Beck RW, Bergenstal RM, et al. Evidence of a strong association between frequency of self-monitoring of blood glucose and hemoglobin A1c levels in T1D exchange clinic registry participants. Diabetes Care 2013;36:2009-14.

35 Wagner J, Malchoff C, Abbott G. Invasiveness as a barrier to selfmonitoring of blood glucose in diabetes. Diabetes Technol Ther 2005;7:612-9.

36 Zambanini A, Feher MD. Needle phobia in type 1 diabetes mellitus. Diabet Med 1997:14:321-3. 
37 Rittmeyer D, Schmid C, Haug C, et al. A novel glucose monitoring system versus a conventional SMBG system: time and step analysis. Paris, France: Poster ATTD-0466. 8th International Conference on Advanced Technologies \& Treatments for Diabetes, 18-21 February 2015.

38 Bilir SP, Hellmund R, Wehler B, et al. Cost-Effectiveness analysis of a flash glucose monitoring system for patients with type 1 diabetes receiving intensive insulin treatment in Sweden. Eur Endocrinol 2018;14:73-9.

39 Gil-Ibáñez MT, Aispuru GR. Análisis de coste-efectividad de control glucémico con FreeStyle Libre $\AA$ en pacientes diabéticos tipo 1 en atención primaria de salud de Burgos. [Cost-effectiveness analysis of glycaemic control of a glucose monitoring system (FreeStyle Libre $\left.{ }^{\circledR}\right)$ for patients with type 1 diabetes in primary health care of Burgos]. Enferm Clin 2019;8621:30295-5.
40 Vellopoulou K, Kourlaba G, Doupis J, et al. Economic Evaluation of Flash Glucose Monitoring Compared To Self - Monitoring of Blood Glucose For The Management of Patients Receiving Intensive Insulin With Diabetes Type 1 And Type 2 In Greece. Value in Health 2017;20:A585-585.

41 Wehler E, Li H, Bilir SP, et al. Cost effectiveness analysis of a flash continuous glucose monitoring system for type 2 diabetes (T2DM) patients receiving intensive insulin treatment in the UK [Abstract]. Value Health 2017;20:A-246.

$42 \mathrm{Li} \mathrm{H}$, Bilir SP, Wehler EA, et al. Cost effectiveness analysis of a flash glucose monitoring system for type 2 diabetes (T2DM) patients receiving intensive insulin treatment in Europe. Value in Health 2016;19:A698-698.

$43 \mathrm{Li} \mathrm{H}$, Bilir SP, Donga P, et al. Cost effectiveness analysis of flash glucose monitoring for type 2 diabetes patients receiving insulin treatment in the UK. Value in Health 2014;17:A351-351. 